\title{
Effect of resistive-endurance exercises on myocardial tissue creatine kinase isoenzyme, IL-6 and IL-10 serum changes in male cardiovascular patients
}

\author{
Alireza ZAMANI ${ }^{1}$, Saeid ROSTAMI², Bijan RAJAEIAN² \\ ${ }^{1}$ Department of Physical Education and Sport Sciences, Islamic Azad University, Dehaghan branch, Dehaghan, Isfahan, Iran. \\ 2 Department of Physical Education and Sport Sciences, Islamic Azad University, Mobarakeh branch, Mobarakeh, Isfahan, Iran. \\ Address Correspondence to S. Rostami, srostami.20@gmail.com
}

\begin{abstract}
The aim of the present study was to investigate the effects of endurance-resistance (concurrent) training on changes of CKmb, interleukin-6, and IL-10 levels of heart disease in men. For this purpose, 38 patients referred to medical centers Cardiovascular Shahin Shahr city, were selected. The patients were underwent bypass surgery or angioplasty balloon. After, patients filled demographic questionnaire and tests were performed to determine risk factors. Also echocardiography (Simpson) and limited exercise test method (Noughton) were used to determine functional capacity and ejection fraction. Before and after the exercise, anthropometric measurements (weight, waist circumference, hip circumference and subcutaneous fat three regions), blood tests for IL-6, IL-10, CKmb and walk test for 6 min (for determining the physical capacity) were measured. The exercises were performed 3 days a week for 24 sessions, each session was one hour. Results showed that rehabilitation programs reduce CKmb and inflammatory cytokines. Totally, the present study showed rehabilitation program having resistance- endurance (concurrent) training can be appropriate in order to perform functional capacity in patients. This method of training can cause improvement in muscular power, $\mathrm{VO}_{2 \max }$ and better cardiovascular performance and at last induce quality of life of patients.
\end{abstract}

Key words: Endurance-resistance training, heart patient, homocysteine, interleukin, rehabilitation.

\section{INTRODUCTION}

Cardiovascular diseases are the most common diseases in the world and one of the leading causes of mortality. Studies suggest that the increased incidence of Coronary heart disease is due to changes in lifestyle $(20,26,27)$. In addition, patients' low welcoming cardiovascular rehabilitation centers due to lack of awareness of the positive effects of therapy (5) necessitates the research projects in this area.

It is well approved that rehabilitation program as a secondary prevention programs for acute coronary artery disease such as myocardial infarction and coronary artery bypass surgery has numerous clinical benefits which Leading to a significant reduction in mortality rates and specific mortality rates caused by cardiovascular disease (22,34). Various studies indicate that $20-25 \%$ of all deaths and about $22-25 \%$ deaths from cardiovascular disease decreased after 3 years of following this program up (33). cardiovascular rehabilitation include physical exercise, lifestyle modification, appropriate medical treatment for men and women, young and old who have been diagnosed with heart disease. The effectiveness of this important therapeutic approach focuses on the wider use of it (8). Physical exercises generally affect cardiovascular risk factors and cardiovascular rehabilitation is a systematic method including exercises and treatment of risk factors and the regular assessment and control of the patients. However, most research has been done on the effect of endurance training $(5,23,30)$, and some research has focused on the role of stress resistance exercise $(12,17)$. It is evident that the above mentioned exercises have unique advantages, but recently the use of current training method has been considered in limited number of articles $(14,27)$ but further research needs to be done on the effect of these training methods on 
cardiovascular disease. CK-MB isoenzyme is one of the most known and valid clinical parameters the increased level of which in blood means cardiac cells damage (19). Most physicians and researchers use the consecutive analysis of this parameter for damage and myocardial infraction diagnosis and use the CK-MB as the key parameter. Some researchers use the ratio of CK-MB to total CK for detailed assessment of myocardial injury and consider the values above 3-5\% as the CK-MB leakage of myocardial cells into blood and the values higher than $20 \%$ as the risk of myocardial cell damage (14).

Cytokines are a group of proteins that play essential roles in inflammatory responses to pathological stimuli such as inflammation and tissue damage. Cytokines are produced by a range of physiological stimuli such as exercise (2). IL-6 as a proinflammatory cytokine involves in the development and progression of inflammation during and especially at the time of the patient's activities. IL10 is also secreted in response to inflammation, and it is considered as an inflammation limiting factor. Both of these factors are predictor of inflammation in the disease. The aim of the present study is to investigate the effects of resistive-endurance exercises on the Homocysteine, serum IL-6 and IL-10 changes of male cardiovascular patient that has not been considered before. Another issue is to determine a strategy for possible changes in the answer. Thus if the rehab exercises can be combined with resistive-endurance exercises to limit heart cells damage parameters or not?

\section{MATERIAL \& METHOD}

This study was a quasi-experimental research the number of the samples of which was 38 patients who referred to medical cardiovascular centers of Shahin Shahr city, chosen among the people who could be in contact.

All of these patients underwent bypass surgery or angioplasty balloon. Patients initially were profiled, the personal data questionnaires were completed and tests were performed to determine their risk factors. Also echocardiography using Simpson method and limited exercise test symptoms using Noughton method were performed in order to determine functional capacity and ejection fraction and determine the risk of a heart disease to recommend an exercise program under the supervision of heart specialist (3). The cases of limitation of taking part in rehabilitation program included: atrial fibrillation, an abnormal sinus node function or in pacemaker patients and patients with severe thyroid disorder. Patient during the exercises should not have Angina and ST segment depression greater than $2 \mathrm{~mL}$ and develop severe chronic heart failure and ejection fraction less than $30 \%$ during the study of electrocardiography and chest radiography. Anthropometric parameters (weight, waist circumference, hip circumference and subcutaneous fat of the three regions), blood tests for IL-6, IL-10 and creatine kinase of myocardial tissue and $6 \mathrm{~min}$ walking test (for determining the physical capacity) were performed before and after the exercise program. The exercise program was 3 days a week for 24 sessions, each session was one hour (24). The subjects had referred to the center one week before the administrative procedures for the physical and physiological testing and besides filling the health history questionnaire (26) they filled the Testimonial Consent Form provided by the Ethics Committee of Isfahan University of Medical Sciences. In this study, physical endurance and resistance exercise based on rehabilitation training program recommended by the American Society of Heart and Lung, American Heart Association and the Medical College of Sports of America (13) for the patient were used. The endurance exercises consisted of 5-10 minutes warmup, 5-10 minutes cool-down period at the end of the workout and the bicycle ergometer 15-20 minutes at 70 to 50 percent of maximum heart rate at the first and then 60-80 percent of maximum heart rate based on Karvonen formula (11). Then, for 15 to 10 minutes the resistance exercise with weights based on the type of heart disease in terms of the safety and effectiveness of the training was performed (5). The intensity of these exercises was based on $20-30 \%$ of maximum repetition and patients exercised 3 sessions a week and were encouraged to do aerobics such as walking for 30 to 45 minutes 1-3 times a week (1). The resistance exercises consisted of 11 moves recommended by the Sports - Cardiovascular College and Pulmonary Rehabilitation Medicine Association of America and the intensity of the exercises was in a way the patient could lift the weights 8-15 times and in case of 15 times of success they would gradually increase the amount of weight lifted (15). Data 
gathering methods included demographic information form, health history questionnaire and record observations regarding the progress of the intensity and duration of exercise for patients. The data were analyzed using the Kolmogorov-Smirnov test and paired sample t-test with SPSS version 17 program.

\section{RESULTS}

All subjects were male, and most of them had undergone coronary artery bypass graft surgery $(50 \%)$. Also, $10 \%$ of patients had hypertension (Table 1).

As can be seen in Table 2, the ejection fraction (EF) of patients was reduced before rehabilitation programs and LV end-systolic diameter(LVESD) and LV end-diastolic echo dimensions (LVEDD) were almost high (normal ranges include: $L V E D D<50 \mathrm{~mm}$ and LVESD $<33 \mathrm{~mm}$ ).

Subjects showed lower aerobic fitness before beginning the rehabilitation program in such a way that the mean resting metabolic (MET) of these patients was only 1.9 based on maximal oxygen uptake (VO2max) of 32.65 milliliters per kilogram per minute (Table 3).

Based on the anthropometric parameters, Table 4 shows that resistive-endurance exercises significantly reduced weight $(\mathrm{P}=0.016)$, abdominal circumference $(\mathrm{P}=0.031)$ hip circumference $(\mathrm{P}=0.003)$ and the total thickness of the subcutaneous fat in three areas

P 0.028 ) respectively. Also it is evident that there significant difference between the distance that patients had passed within 6 minutes before and after the rehabilitation program $(\mathrm{P}=0.001)$.

Table 1. Distribution of the study sample in terms of medication and treatment.

\begin{tabular}{llcc}
\hline Variable & & No & Percent \\
\hline \multirow{4}{*}{ Medications } & Antihypertensive & 3 & $\% 10$ \\
& Anti-lipid & 6 & $\% 15$ \\
& NTG group & 15 & $\% 40$ \\
Type of treatment & Aspirin and anticoagulants. & 14 & $\% 35$ \\
& Artery Bypass Surgery & 19 & $\% 50$ \\
& Valve Replacement Surgery & 1 & $\% 6$ \\
& Angioplasty & 18 & $\% 44$ \\
\hline
\end{tabular}

Table 2. Echocardiographic parameters of the subjects before beginning a rehabilitation program.

\begin{tabular}{lcc}
\hline Variable & Mean & SD \\
\hline & & \\
Ejection fraction & 51.45 & 12.31 \\
Left ventricular end diastolic size $(\mathrm{ml})$ & 39.67 & 6.98 \\
Left ventricular end-systolic size $(\mathrm{ml})$ & 51.45 & 6.61
\end{tabular}

Table 3. Parameters obtained by the subjects during exercise.

\begin{tabular}{lcc}
\hline Variable & Mean & SD \\
\hline & & \\
Resting systolic blood pressure (mmHg ml) & 129.8 & 4 \\
Resting diastolic blood pressure (ml) & 71.6 & 6 \\
Maximum systolic blood pressure & 163.1 & 12 \\
Diastolic Blood Pressure & 84.6 & 5 \\
Resting metabolic equivalent (MET) & 9.1 & 2.76 \\
& & \\
\hline
\end{tabular}

Table 4. The effect of rehabilitation on anthropometric parameters for 6-minute walk test in patients.

\begin{tabular}{|c|c|c|c|c|c|}
\hline \multirow[t]{2}{*}{ Variable } & \multicolumn{2}{|c|}{$\begin{array}{c}\text { Before rehabilitation } \\
\text { program }\end{array}$} & \multicolumn{2}{|c|}{$\begin{array}{l}\text { After rehabilitation } \\
\text { program }\end{array}$} & \multirow{2}{*}{$\begin{array}{c}\text { Level of } \\
\text { significance }\end{array}$} \\
\hline & Mean & SD & Mean & SD & \\
\hline Weight $(\mathrm{kg})$ & 81.3 & 19.1 & 72.6 & 5.6 & 0.016 \\
\hline Abdominal circumference $(\mathrm{cm})$ & 97.6 & 11.2 & 88.1 & 7.6 & 0.031 \\
\hline Hip circumference $(\mathrm{cm})$ & 117.4 & 13.6 & 9.8 & 8.7 & 0.003 \\
\hline The sum of the thickness of subcutaneous fat $(\mathrm{mm})$ in 3 areas & 78.9 & 68.5 & 59.8 & 18.9 & 0.028 \\
\hline Walk test $(\mathrm{m})$ & 478 & 29.6 & 598 & 63.9 & 0.001 \\
\hline
\end{tabular}

Table 5. The effect of rehabilitation on the levels of inflammatory cytokines and CKMB.

\begin{tabular}{lccccc}
\hline Variable & \multicolumn{2}{c}{ Before rehabilitation program } & \multicolumn{2}{c}{ after rehabilitation program } & Sevel of significance \\
\cline { 2 - 3 } & Mean & SD & Mean & & \\
CK-MB $(\mathrm{Ng} \mathrm{mL})$ & 259.6 & 78.4 & 149.8 & 98.1 & 0.001 \\
IL-6 (Ng mL) & 6.6 & 2.4 & 2.1 & 2.6 & 0.004 \\
IL-10 (Ng mL) & 10.7 & 2.9 & 3.8 & 1.7 & 0.026 \\
& & & & \\
\hline
\end{tabular}

Turk ل Spart Exe 2015; 17(1): 7-11

๑ 2015 Faculty of Sport Sciences, Selcuk University 
According to Table 5, the rehabilitation program was effective in reducing inflammatory cytokine and creatine kinase of myocardial tissue and has resulted in a significant reduction in their levels.

The results showed that the activity of CK-MB isoenzyme has decreased significantly. In this regard most studies are focused on the impact of physical activities on the mentioned parameters and few of them have considered the long-term effects of exercise rehabilitation on cardiovascular patients. There is a possibility of myocardial cell membrane vulnerability and increased risk of CK_MB isoenzyme leakage into the bloodstream after the outbreak of the disease (similar to strenuous and long term activities) which will drop to lower values after adjustment to the exercise. The results of previous studies on exercise and rehabilitation exercises with low intensity are different. However some investigation after the Triple Iron Men competitions, Alps trekking for two days and 100 kilometers of racing, have shown the increase in the parameter that are not in line with this research $(10,31,32)$. Perhaps one of the reasons for this is the high endurance nature of those investigations. Also other studies with endurance nature did not show significant differences. This might be due to the type of activity. However, CK-MB as marker of myocardial damage in these patients is high and due to the longterm activities the primary level has been reduced.

The results of our study showed that this method of exercise decreased the IL-6 and IL-10. Several studies have been studied the relationship between physical activity and plasma levels of inflammatory parameters. For example Fernandez et al. observed that IL-6 levels are inversely associated with exercise tolerance in the older and disabled women (9). Some researchers have stated that individuals who are more physically active and physically ready to do more have less concentrations of inflammatory index compared with the passive and immobile people. Possible mechanisms that reduce the sources of inflammation may be because obesity (due to the production and expression of TNF-a, IL-6 gene and its receptors) is a factor that is strongly associated with high levels of inflammation (6). Therefore, reducing body fat and increasing lipolysis in rehabilitation exercises (stimulating HSL hormone-sensitive lipase) could be a mechanism by which inflammation is reduced. Generally, this study while confirming the results of the previous studies, indicated that the rehabilitation program using resistive-endurance exercises and based on the effectiveness of these methods, may be an effective method for improving functional capacity in coronary patients. This exercise method can improve the lifestyle of the coronary patients through improving muscular strength and greater impact on cardiovascular improvement induced by power exercises and improving maximal oxygen uptake and higher cardiopulmonary readiness induced by endurance exercises. Also, due to the effect of resistance exercises on left ventricular structure and hypertension, it is recommended that similar research be done on the impact of these two methods of rehabilitation training on left ventricular structure, heart rate and high blood pressure of cardiovascular patients.

\section{REFERENCES}

1. Adams J, Cline MJ, Hubbard M, McCullough T, Hartman J. A new paradigm for post-cardiac event resistance exercise guidelines. AM J Cardiol 2006; 97(2): 281-286.

2. Anderson JL, Muhlestein JB, Horne BD, et al. Plasma homocysteine predicts mortality independently of traditional risk factors and Creactive protein in patients with angiographically defined coronary artery disease. Circulation 2000; 102(11): 1227-1232.

3. Bots ML, Launer LJ, Lindemans J, et al. Homocysteine, atherosclerosis and prevalent cardiovascular disease in the elderly: The Rotterdam Study. J Intern Med 1997; 242(4): 339347.

4. Burtis CA, Ashwood ER, Brouns DE. Clinical chemistry and molecular diagnostics. 4th ed. USA: Elsevier; 2006; 118-121.

5. Choo J, Burke LE, Hong K.P. Improved quality of life with cardiac rehabilitation for post-myocardial infarction patients in Korea. European Journal of Cardiovascular Nursing 2007; 6 (3): 166-177.

6. Christen WG, Ajani UA, Glynn RJ, Hennekens CH. Blood levels of homocysteine and increased risks of cardiovascular disease: causal or casual? Arch Intern Med 2006; 160(4): 422-434.

7. Danesh J, Lewington S. Plasma homocysteine and coronary heart disease: systematic review of published epidemiological studies. J Cardiovasc Risk 2009; 5(4): 229-232.

8. Erfurt JC, Holtyn K. Health promotion in small business what works and what doesn't work. J Occup Med 1991; 33:66-73.

9. Fernandez - Real JM, Vayreda M, Richard C, Gutierrez C, Broch $\mathrm{M}$, vendrell J, Ricart W. Circulating interleukin levels, blood pressure and insulin sensitivity in apparently healthy men and women. J Clin endocrinol Metab 2001; 86: 1154-1159.

10. Ford ES, Smith SJ, Stroup DF, Steinberg KK, Mueller PW, Thacker SB. Homocyst(e)ine and cardiovascular disease: a systematic review of the evidence with special emphasis on 
case-control studies and nested case-control studies. Int J Epidemiol 2002; 31(1): 59-70.

11. Franklin BA, Kahn JK, Gordon NF, Bonow RO. A cardioprotective "polypill"? Independent and additive benefits of lifestyle modification. The American Journal of Cardiology 2004; 94(2):162-166.

12. Freimark D, Shechter M, Schwamenthal E, Tanne D, Elmaleh E, Shemesh Y, et al. Improved exercise tolerance and cardiac function in severe chronic heart failure patients undergoing a supervised exerciseprogram. Int J Cardiol 2007; 116(3, 4): 309_ 314.

13. Gayda M, Brun C, Juneau M, Levesque S, Nigam A. Long-term cardiac rehabilitation and exercise training programs improve metabolic parameters in metabolic syndrome patients with and without coronary heart disease. Nutrition, Metabolism and Cardiovascular disease 2008; 18(2): 142-151.

14. George NW, Joseph L. Homocystein and Atherothrombosis. New Engl J Med 1998; 338(15): 1042-1050.

15. Glowacki SP, Martin SE, Maurer A, Baek W. Effects of resistance, endurance, and concurrent exercise on training outcomes in men. Med Sci Sports Exerc 2004; 36 (12): 2119-27.

16. Heyward Vivian H. Advance fitness assessment and exercise prescription. 3rd Edition. The Cooper Institute for Aerobics Research. DallasTX: Advance Fitness Assessment \& Exercise Prescription. 1998: 48.

17. Jankowska EA, Wegrzynowska K, Superlak M, Nowakowska K, Lazorczyk M, Biel B, et al. The 12-week progressive quadriceps resistance training improves muscle strength, exercise capacity and quality of life in patients with stable chronic heart failure. International Journal of Cardiology 2007; 89: $114-120$

18. Karapolat H, Eyigör S, Zoghi M, Yagd T, Nalbangil S, Durmaz B. Comparison of hospital-supervised exercise versus homebased exercise in patients after orthotopic heart transplantation: effects on functional capacity, quality of life, and psychological symptoms. Transplantation Proceedings 2007; 39 (5): 1586-1588.

19. Kida K, Osada N, Akashi YJ, Sekizuka H, Omiya K, Miyake F. (2008). The exercise training effects of skeletal muscle strength and muscle volume to improve functional capacity in patients with myocardial infarction. International Journal of Cardiology 2008; 14: 28-37.

20. Kumaran K, Fall CHD, Martyn CN, Vijayakumar M, Stein C, Shier R. Left ventricular mass and arterial compliance: relation to coronary heart disease and its risk factors in South Indian adults. International Journal of Cardiology 2008; 83(1): 1-9.

21. Lavie CJ, Morshedi-Meibodi A, Milani RV. Impact of cardiac rehabilitation on coronary risk factors, inflammation, and the metabolic syndrome in obese coronary patients. J Cardiometab Syndr 2008; 3 (3):136-140.

22. Leon AS, Franklin BA, Costa F, Balady GJ, Berra KA, Stewart $\mathrm{KJ}$, et al. Cardiac rehabilitation and secondary prevention of coronary heartdisease. Circulation 2005; 111:369-376.
23. MacMillan JS, Davis LL, Durham CF, Matteson ES. Exercise and heart rate recovery. Heart \& Lung: The Journal of Acute and Critical Care 2006; 35 (6): 383-390.

24. Pashkow FJ, Dafce WA. Clinical cardiac rehabilitation $2^{\text {nd }}$ edition, Baltimore: Williams and Wilkins: 1999; 458-66.

25. Pezshkeyan M, Norri M, Refahi R, Afrasiabi A, Rahbani M, Qujeq D. Relationship between hyperhomocysteinemia and oxidative stress with severity of atherosclerotic lesion. J Med Sci 2005; 5(4): 243-246.

26. Ritchie Gemma M, Keech AC, ASPAC Collaborative Group. Asia- pacific collaboration on coronary heart disease risk factor intervention: Study design and methods. Heart, Lung and Circulation 2001; 10 (1): 24-29.

27. Rostami S, Faramarzi M, Arbab G. Effect of two methods of training on some plasma level of inflammatory cytokines in youth soccer players. Journal of medical university of Hormozgan 2014; 13; 87-96.

28. Schmidt WD, Biwer CJ, Kalscheuer LK. Effects of long versus short bout exercise on fitness and weight loss in overweight females. Journal of the American College of Nutrition 2001; 20 (5): 494-501.

29. Selhub J, Jacques PF, Rosenberg IH, Rogers G, Bowman BA, Gunter EW, et al. Serum total homocysteine concentrations in the third National Health and Nutrition Examination Survey (1991-1994): population reference ranges and contribution of vitamin status to high serum concentrations. Ann Intern Med 1999; 131(5): 331-339.

30. Shi L. The impact of increasing intensity of health promotion intervention on risk reduction. Eval Health Prof 1992; 15(1):325.

31. Smith JK, Dykes R, Douglas JE, Krishnaswamy G, Bork S. Long term exercise and atherogenic activity of blood mononuclear cells in persons at risk of developing ischemic heart disease. JAMA 2007; 281: 1722-1727.

32. Sykes K, Choo LL, Cotterrell M. Accumulating aerobic exercise for effective weight control. J R Soc Health 2004; 124 (1): 24-8.

33. Taylor RS, Brown A, Ebrahim S, Jolliffe J, Noorani H, et al. Exercise- based rehabilitation for patients with coronary heart disease: systematic review and meta-analysis of randomized controlled trials, Am J Med 2004; 116 (10): 682-692.

34. Thompson PD, Franklin BA, Balady GJ, Blair SN, Corrado D, Estes $\mathrm{M}$, et al. Exercise and Acute cardiovascular events. AHA; ACSM, 2007.

35. Ueland PM, Refsum H, Beresford SA, Vollset SE. The controversy over homocysteine and cardiovascular risk. Am J Clin Nutr 2010; 72(2): 324-332.

36. Wannamethee SG, Lowe GD, Whincup PH, Rumley A, Walker M, Lennon L. Physical activity and hemostatic and inflammatory variables in elderly men. Circulation 2002; 105: 1785-1790. 